Jurnal Pemberdayaan: Publikasi Hasil Pengabdian kepada Masyarakat

Vol. 2, No. 1, April 2018, Hal. 159-164

ISSN: 2088 4559; e-ISSN: XXXX-XXXX

\title{
DOI:
}

\section{PEMBERDAYAAN MASYARAKAT DESA KEMIRI, TANJUNGSARI, GUNUNGKIDUL : PROGRAM PELATIHAN MEMASAK BERBAHAN DASAR MOCAF}

\author{
Sudarmini dan Destra Aulia Azizah \\ Universitas Ahmad Dahlan, Yogyakarta \\ sudarmini@pbsi.uad.ac.id
}

\begin{abstract}
ABSTRAK
Desa Kemiri, Kecamatan Tanjungsari, Kabupaten Gunungkidul, Daerah Istimewa Yogyakarta merupakan salah satu desa yang mempunyai usaha pengolahan tepung mocaf yang telah menampakkan hasil dan sudah menjadi usaha pada sektor rumah tangga. Tepung mocaf dapat dijadikan sebagai salah satu alternatif bahan baku utama sebagi pengganti tepung terigu. Maka program KKN UAD difokuskan pada pelatihan mengolah tepung mocaf menjadi produk konsumsi yang bernilai ekonomis. Program ini bertujuan memberdayakan masyarakat Desa Kemiri dalam program pelatihan mengolah tepung mocaf. Metode pelaksanaan program KKN meliputi: pembekalan masyarakat, pelatihan dasar dan praktik langsung. Dampak dari kegiatan KKN ini adalah : 1) peningkatan pengetahuan masyarakat dalam mengolah makanan berbahan dasar tepung mocaf, 2) masyarakat terampil membuat makanan kreatif berbahan dasar tepung mocaf, dan 3 ) tersedianya pengganti bahan baku tepung terigu.
\end{abstract}

Kata kunci : pemberdayaan, masyarakat, desa Kemiri, pelatihan, mocaf

\begin{abstract}
Kemiri Village, Tanjungsari District, Gunungkidul Regency, Special Region of Yogyakarta is one of the villages that has a mocaf flour processing business that has shown results and has become a business in the household sector. Mocaf flour can be used as an alternative to the main raw material as a substitute for wheat flour. So the UAD KKN program is focused on training to process mocaf flour into economically valuable consumer products. This program aims to empower the Kemiri Village community in a training program to process mocaf flour. The methods for implementing the KKN program include: community debriefing, basic training and direct practice. The impacts of this KKN activity are: 1) increasing community knowledge in processing food made from mocaf flour, 2) the community is skilled at making creative food made from mocaf flour, and 3) the availability of substitutes for raw materials for flour.
\end{abstract}

Keywords: empowerment, community, Kemiri village, training, mocaf 


\section{PENDAHULUAN}

Desa Kemiri merupakan salah satu desa di kecamatan Tanjungsari, Gunungkidul. Desa ini terletak di sebelah utara Desa Kemadang, Desa Banjarejo, Desa Ngestirejo dan sebelah barat Desa Hargosari. Desa Kemiri memiliki 11 Padukuhan, 11 Rukun Warga dan 48 Rukun Tetangga. Masyarakat Desa Kemiri yang sebagian besar berprofesi sebagai petani. Salah satu produk pertanian yang paling banyak ditemukan di Desa Kemiri adalah singkong. Beberapa permasalahan yang ditemukan di Desa Kemiri adalah : 1) Kurang dimanfaatkannya singkong sebagai bahan baku pembuatan makanan, 2) Kurangnya pengetahuan masyarakat dalam mengolah tepung mocaf menjadi makanan bernilai ekonomis, 3) Kurangnya keterampilan masyarakat dalam mengolah tepung mocaf menjadi makanan menarik, 4) Kurangnya pengetahuan masyarakat tentang pemasaran produk dari mocaf. Menginngat banyaknya masyarakat yang belum mampu mengolah tepung singkong fermentasi (mocaf), maka diperlukan upaya pemberdayaan melalui pelatihan keterampilan agar masyarakat mampu berwirausaha dengan bahan baku tersebut.

Tepung mocaf merupakan tepung yang terbuat dari singkong yang difermentasi dengan mikroba. Beberapa mikroba yang sudah digunakan untuk menghasilkan tepung mocaf antara lain Aceptobacter xylinum (Salim, 2011). Penggunaan mocaf sebagai tepung alternatif pengganti terigu dalam membuat berbagai produk pangan telah banyak dilakukan, seperti dalam pembuatan mie basah dan mie kering (Rosmeri, 2013). Tepung mocaf memiliki kandungan nutrisi yang berbeda dengan tepung terigu. Perbedaan kandungan nutrisi yang mendasar adalah tepung mocaf tidak mengandung gluten. Peluang pemanfaatan tepung mocaf sebagai bahan baku berbagai produk olahan seperti halnya tepung terigu mulai terbuka lebar. Tepung mocaf dengan bahan baku lokal mempunyai peluang untuk dimanfaatkan sebagai bahan baku produk olahan pangan yang mensubstitusi tepung terigu.

Berdasarkan permasalahan tersebut, maka ditetapkan tujuan program KKN ini adalah memberdayakan masyarakat Desa Kemiri dalam mengolah makanan berbahan dasar tepung mocaf. 


\section{METODE}

Program Pelatihan Pengolahan Makanan Berbahan Dasar Tepung Mocaf dilaksanakan pada bulan Februari 2018 selama 1 bulan di Desa Kemiri, Kecamatan Tanjungsari, Kabupaten Gunungkidul. Metode yang digunakan yaitu melalui pembekalan masyarakat, pelatihan dasar dan praktik langsung. Ringkasan metode pelaksanaan beserta jam kerja efektif mahasiswa (JKEM) tersaji pada tabel 1 .

Tabel 1. Metode, Kegiatan dan JKEM

\begin{tabular}{|c|c|c|c|}
\hline No. & Metode & Kegiatan & JKEM \\
\hline 1. & $\begin{array}{l}\text { Pembekalan } \\
\text { Masyarakat }\end{array}$ & $\begin{array}{l}\text { Menyelenggarakan penyuluhan } \\
\text { pengolahan makanan berbahan } \\
\text { dasar mocaf dalam tingkat desa }\end{array}$ & $1 \times 100$ menit \\
\hline 2. & Pelatihan Dasar & $\begin{array}{l}\text { Menyelenggarakan Pelatihan } \\
\text { pengolahan makanan berbahan } \\
\text { dasar mocaf dalam tingkat desa }\end{array}$ & $1 \times 100$ menit \\
\hline \multirow[t]{5}{*}{3.} & \multirow{5}{*}{$\begin{array}{l}\text { Praktik } \\
\text { Langsung }\end{array}$} & Pembuatan Brownis & $1 \times 100$ menit \\
\hline & & Pembuatan Kripik Sayur & $1 \times 200$ menit \\
\hline & & Pembuatan Sup Mocaf & $1 \times 100$ menit \\
\hline & & Pembuatan Stik Mocaf & $1 \times 100$ menit \\
\hline & & Pembuatan Pisang Coklat & $1 \times 100$ menit \\
\hline
\end{tabular}

\section{HASIL, PEMBAHASAN DAN DAMPAK}

Jumlah penduduk di Desa Kemiri yaitu 4.351 jiwa dengan perbandingan 2.026 laki-laki dan 2.325 perempuan. Tingkat pendidikan di Desa Kemiri masih tergolong rendah, hanya beberapa orang yang melanjutkan pendidikannya kejenjang lebih tinggi. Jumlah penduduk dengan tingkat pendidikan terendah tidak sekolah mencapai angka 1.152 jiwa, belum tamat SD sebanyak 310 jiwa, tamat SD sebanyak 1.578 jiwa, jenjang SLTP sebanyak 941 jiwa, jenjang SLTA sebanyak 404 jiwa, Diploma I dan II sebanyak 28 jiwa, Diploma II sebanyak 21 jiwa, Diploma IV dan Sastra I sebanyak 40 jiwa, Strata II sebanyak 1 jiwa dan Strata III sebanyak 0 jiwa. Komposisi penduduk berdasarkan tingkat pendidikannya dapat dilihat pada gambar 1 . 


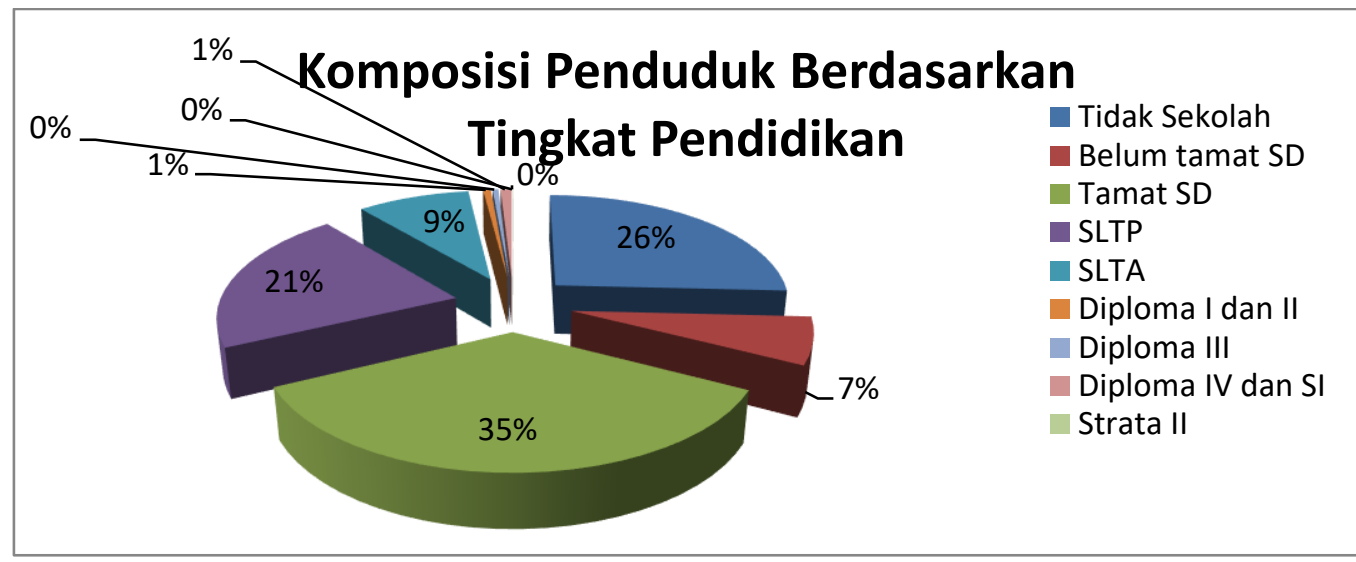

Gambar 1. Komposisi Penduduk Berdasarkan Tingkat Pendidikan.

Tenaga kerja yang terdapat di Desa Kemiri bervariatif, dengan beragam mata pencaharian diantaranya Pegawai Negeri Sipil (PNS), wiraswasta, peternak dan lain sebagainya. Akan tetapi sebagian besar penduduk bermatapencaharian sebagai petani ladang.

Hasil pertanian di Desa Kemiri menurut data pada tahun 2016 yaitu lahan seluas 300 hektar untuk produksi padi pertahun sekitar 1.410 ton, luas lahan 424 hektar untuk produksi jagung pertahun sekitar 15.600 ton, luas lahan 424 hektar untuk produksi singkong pertahun sekitar 9.031,6 ton, luas lahan 210 hektar untuk produksi kacang tanah pertahun sekitar 2.255 ton. Hasil pertanian di Desa Kemiri dapat dilihat pada Gambar 2.

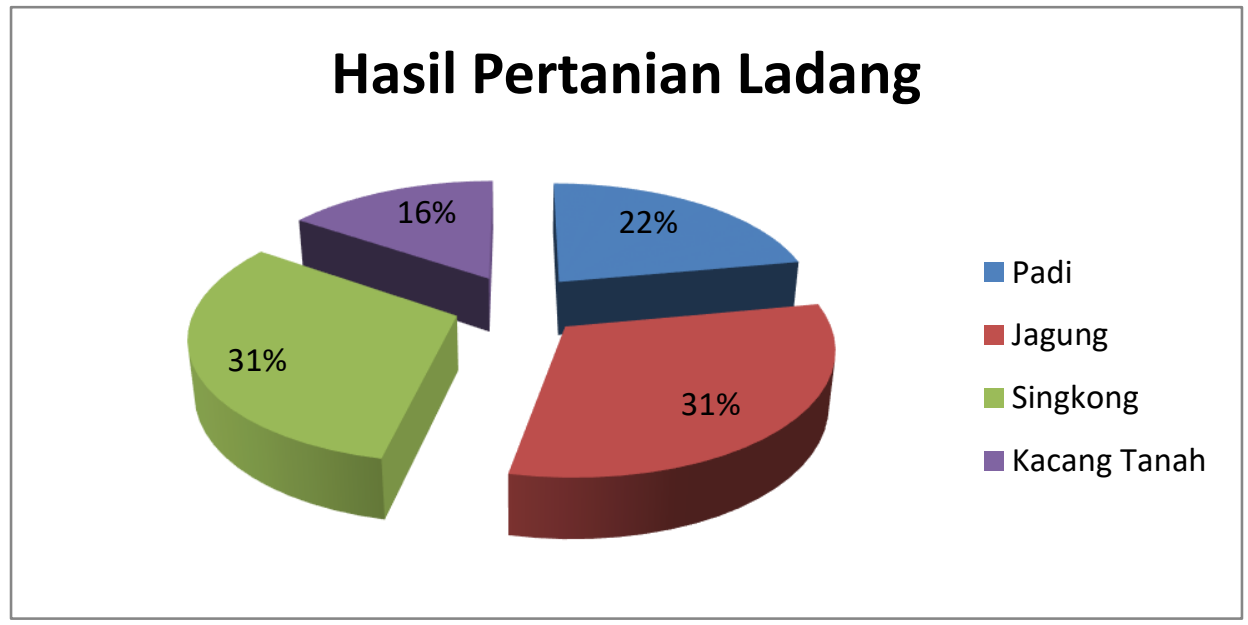

Gambar 2. Hasil pertanian di Desa Kemiri

Gambaran Pelaksanaan 
Berikut beberapa aktivitas mahasiswa KKN UAD dan masyarakat Desa Kemiri dalam program pelatihan pengolahan makanan berbahan dasar mocaf tersaji pada gambar 3. Produk olahan pada gambar 3 yaitu brownis dibuat dari bahan baku tepung mocaf, teksturnya hampir sama dengan tepung terigu sehingga dapat digunakan sebagai pengganti tepung terigu. Sedangkan untuk karakteristiknya, tepung mocaf berbeda dengan tepung yang terbuat dari umbiumbian yang lain, karena dibuat melalui fermentasi yang menghasilkan tepung cassava yang memiliki tekstur lebih halus dan lebih mekar untuk diolah menjadi makanan (Suismono et al, 2007 dalam Misgiyarta et al, 2010).

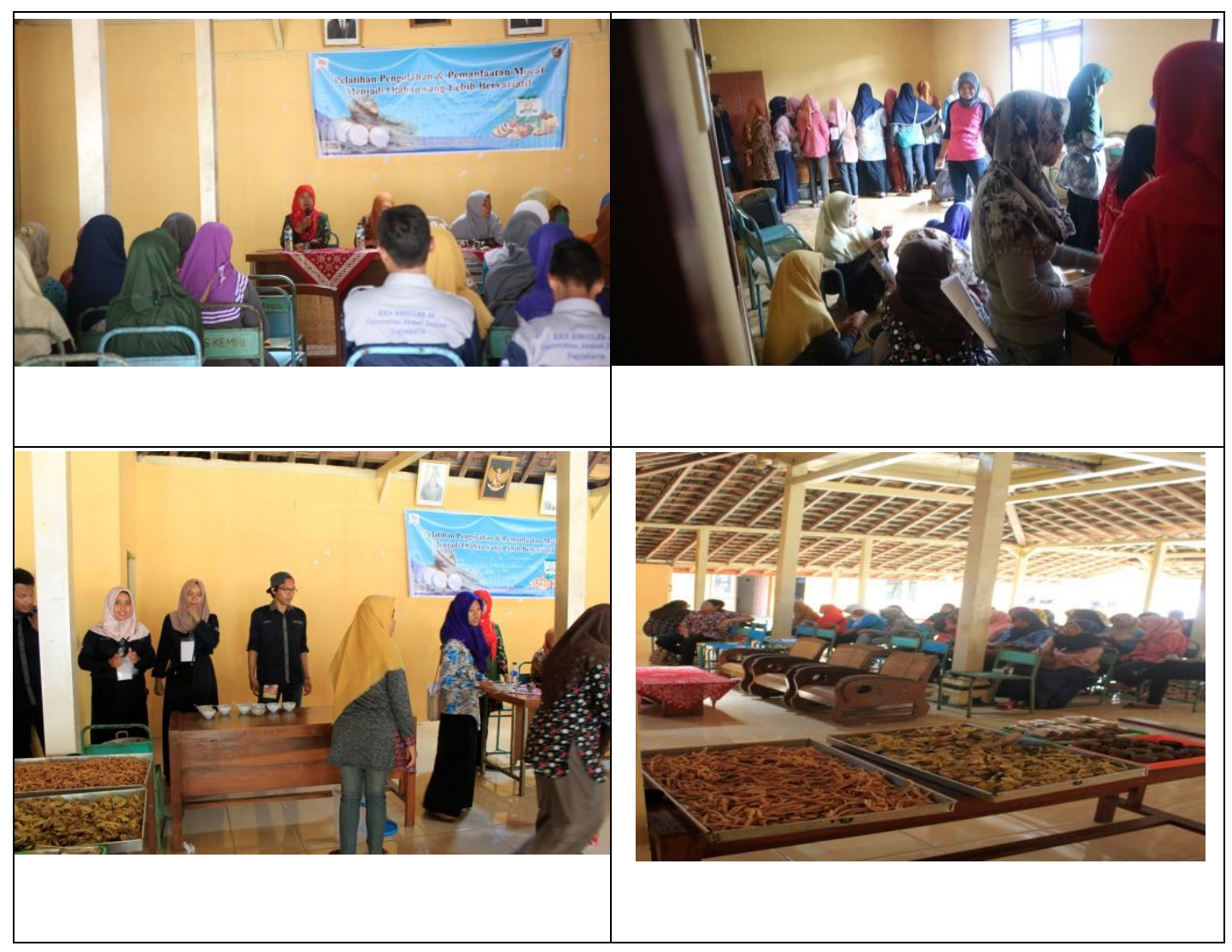

Gambar 3. Aktivitas mahasiswa KKN UAD dan masyarakat Desa Kemiri dalam program pelatihan memasak berbabahan dasar mocaf.

Berdasarkan gambar 3 terlihat program KKN di Desa Kemiri dapat terlaksana karena partisipasi masyarakat yang tinggi dengan kata lain dapat memperdayakan masyarakat dalam program-program yang telah direncanakan. Dampak dari 


\section{8}

kegiatan $\mathrm{KKN}$ ini adalah : 1) meningkatkan pengetahuan masyarakat dalam mengolah makanan berbahan dasar tepung mocaf, 2) masyarakat terampil membuat makanan kreatif berbahan dasar tepung mocaf, 3) tersedianya pengganti bahan baaaku tepung terigu.

\section{SIMPULAN}

KKN merupakan salah satu bentuk pengabdian yang melibatkan antara mahasiswa dan masyarakat. Dalam hal ini, KKN Reguler UAD periode 65 memiliki tujuan untuk memberdayakan masyarakat salah satunya di Desa Kemiri dalam bentuk pelatihan. Program tersebut berupa kegiatan pengolahan makanan berbahan dasar mocaf. Adapun produk yang dihasilkan dari kegiatan pengolahan berbahan dasar mocaf antara lain: brownis, keripik sayur, sup mocaf, stik mocaf, pisang coklat, dan lain-lain.

\section{DAFTAR PUSTAKA}

Misgiyarto, Suismono, Nur Richana, Suyanti, 2010. Penelitian dan Pengembangan Produk Berbasis Ubikayu. Kumpulan Makalah Seminar, Pengembangan Industri Pengolahan Singkong Terpadu. Semarang, 21 Juli 2010. ISBN: 978-602-973-22-3-6.

Rosmeri, Iv. 2013. Pemanfaatan Tepung Umbi Gadung (Dioscorea hispida Desnnst) dan Tepung MOCAF (Modified Cassava Flour) Sebagai Bahan Substitusi dalam Pembuatan Mie Basah, Mie Kering dan Mie Instan. Jurnal Teknologi Kimia dan Industri. Vol.2, No. 2: 246: 256.

Salim, E. 2011. Mengolah Singkong Menjadi Tepung Mocaf. Yogyakarta. Lily Publisher. Hal. 4-55.

\section{UCAPAN TERIMA KASIH}

1. Pemerintah Desa Kemiri, Tanjungsari GK

2. Masyarakat Desa Kemiri, Tanjungsari GK

3. LPPM Universitas Ahmad Dahlan Yogyakarta 